\title{
Jellyfish extract induces apoptotic cell death through the p38 pathway and cell cycle arrest in chronic myelogenous leukemia K562 cells
}

\author{
Sun-Hyung Ha ${ }^{1}$ ， Fansi Jin ${ }^{2}$, Choong-Hwan Kwak ${ }^{1}$ ， Fukushi Abekura ${ }^{1}$ ， Jun-Young Park ${ }^{1}$, Nam Gyu Park ${ }^{3}$ \\ Young-Chae Chang ${ }^{4}$, Young-Choon Lee ${ }^{5}$, Tae-Wook Chung ${ }^{6}$, Ki-Tae Ha ${ }^{6}$, Jong-Keun Son ${ }^{2}$, Hyeun Wook \\ Chang ${ }^{2}$, Cheorl-Ho Kim ${ }^{\text {Corresp. } 1}$ \\ 1 Molecular and Cellular Glycobiology Unit, Department of Biological Sciences, Sungkyunkwan University, Suwon City, Kyunggi-Do, Korea \\ 2 College of Pharmacy, Yeungnam University, Gyeongsan, North Gyeongsang, South Korea \\ 3 Department of Biotechnology, College of Fisheries Sciences, Pukyung National University, Busan, Korea \\ 4 Research Institute of Biomedical Engineering and Department of Medicine, Catholic University of Daegu, Daegu, Republic of Korea \\ 5 Department of Medicinal Biotechnology, College of Health Science, Dong-A University, Busan, Korea \\ 6 Division of Applied Medicine, School of Korean Medicine, Pusan National University, Yangsan City, Gyeongsangnam-Do, Republic of Korea \\ Corresponding Author: Cheorl-Ho Kim \\ Email address: chkimbio@skku.edu
}

Jellyfish species are widely distributed in the world's oceans, and their population is rapidly increasing. Jellyfish extracts have several biological functions, such as cytotoxic, antimicrobial, and antioxidant activities in cells and organisms. However, the anti-cancer effect of Jellyfish extract has not yet been examined. We used chronic myelogenous leukemia K562 cells to evaluate the mechanisms of anti-cancer activity of hexane extracts from Nomura's jellyfish in vitro. In this study, jellyfish are subjected to hexane extraction, and the extract is shown to have an anticancer effect on chronic myelogenous leukemia K562 cells. Interestingly, the present results show that jellyfish hexane extract (Jellyfish$\mathrm{HE}$ ) induces apoptosis in a dose- and time-dependent manner. To identify the mechanism(s) underlying Jellyfish-HE-induced apoptosis in K562 cells, we examined the effects of Jellyfish-HE on activation of caspase and mitogen-activated protein kinases (MAPKs), which are responsible for cell cycle progression. Induction of apoptosis by Jellyfish-HE occurred through the activation of caspases-3,-8 and -9 and phosphorylation of p38. Jellyfish-HE-induced apoptosis was blocked by a caspase inhibitor, Z-VAD. Moreover, during apoptosis in K562 cells, p38 MAPK was inhibited by pretreatment with SB203580, an inhibitor of p38. SB203580 blocked jellyfish-HE-induced apoptosis. Additionally, Jellyfish-HE markedly arrests the cell cycle in the G0/G1 phase. Therefore, taken together, the results imply that the anti-cancer activity of Jellyfish-HE may be mediated apoptosis by induction of caspases and activation of MAPK, especially phosphorylation of p38, and cell cycle arrest at the Go/G1 phase in K562 cells. 
1 Running title: Jellyfish and anti-tumor potentials

2

3 Jellyfish extract induces apoptotic cell death through the p38 pathway and cell cycle arrest in 4 chronic myelogenous leukemia K562 cells

5

6 Sun-Hyung Ha (sunspring5@naver.com $)^{1 \#, ~ F a n s i ~ J i n ~(k i m f a n s i @ g m a i l . c o m) ~}{ }^{2 \#}$, Choong-Hwan 7 Kwak (hahaaaa@nate.com) ${ }^{1}$, Fukushi Abekura (pokusa6@hotmail.com)1, Jun-Young Park $8 \quad$ (wnsdud2057@naver.com) $^{1}, \quad$ Nam-Gyu Park $\quad$ ngpark@pknu.ac.kr $)^{3}, \quad$ Young-Chae Chang $9 \quad$ (ycchang@cu.ac.kr $^{4}, \quad$ Young-Choon Lee $\quad(\underline{\text { yclee@dau.ac.kr }})^{5}, \quad$ Tae-Wook Chung Hyeun Wook Chang (hwchang@yu.ac.kr $)^{2^{*}}$ and Cheorl-Ho Kim (chkimbio@skku.edu) $)^{{ }^{*}}$

${ }^{1}$ Molecular and Cellular Glycobiology Unit, Department of Biological Sciences, SungKyunKwan University, 2066, Seobu-Ro, Jangan-Gu, Suwon City, Kyunggi-Do 16419, Korea.

${ }^{2}$ College of Pharmacy, Yeungnam University, Korea

${ }^{3}$ Department of Biotechnology, College of Fisheries Sciences, Pukyung National University, Busan 48513,

17 Republic of Korea

${ }^{4}$ Research Institute of Biomedical Engineering and Department of Medicine, Catholic University of Daegu School of Medicine, Daegu, Republic of Korea

${ }^{5}$ Department of Medicinal Biotechnology, Dong-A University, Busan, Republic of Korea

${ }^{6}$ Division of Applied Medicine, School of Korean Medicine, Pusan National University, Yangsan City, Gyeongsangnam-Do, Republic of Korea 
23 \# The authors equally contributed to the study as co-first authors.

24 *Corresponding author: Prof. Cheorl-Ho Kim. Department of Biological Sciences, Sungkyunkwan

25 University, Jangan-Gu, Suwon City, Kyunggi 16419, Korea. Tel: +82-31-290-7002. Fax: +82-31-290-

26 7015. Email: chkimbio@skku.edu

*Co-corresponding author: Prof. HW Chang, College of Pharmacy, Yeungnam University, Korea

Email: hwchang@yu.ac.kr

Abbreviations: Jellyfish-HE, Jellyfish hexane extract; CML, chronic myelogenous leukemia; MAPK, mitogen-activated protein kinase; DR, death receptor; CDK, cyclin dependent kinase; DMSO, dimethyl sulfoxide; MTT, 3-(4,5-dimethylth-iazol-2-yl)-2,5-diphenyltetrazolium bromide; DAPI, 6-diamidino-2phenylindole dihydrochloride; PMSF, phenylmethylsulfonyl fluoride; SDS-PAGE, sodium dodecyl sulfate-polyacrylamide gel electrophoresis; FBS, fetal bovine serum.

\section{Abstract}

Jellyfish species are widely distributed in the world's oceans, and their population is rapidly increasing. Jellyfish extracts have several biological functions, such as cytotoxic, anti-microbial, and antioxidant activities in cells and organisms. However, the anti-cancer effect of Jellyfish extract has not yet been examined. We used chronic myelogenous leukemia K562 cells to evaluate the mechanisms of anti-cancer activity of hexane extracts from Nomura's jellyfish in vitro. In this study, jellyfish are subjected to hexane extraction, and the extract is shown to have an anticancer effect on chronic myelogenous leukemia K562 cells. Interestingly, the present results show that jellyfish hexane extract (Jellyfish-HE) induces apoptosis in a dose- and time-dependent manner. To identify the mechanism(s) underlying Jellyfish-HE-induced apoptosis in K562 cells, we examined the effects of Jellyfish-HE on activation of caspase and mitogen- 
46

47

activated protein kinases (MAPKs), which are responsible for cell cycle progression. Induction of apoptosis by Jellyfish-HE occurred through the activation of caspases-3,-8 and -9 and phosphorylation of p38. Jellyfish-HE-induced apoptosis was blocked by a caspase inhibitor, Z-VAD. Moreover, during apoptosis in K562 cells, p38 MAPK was inhibited by pretreatment with SB203580, an inhibitor of p38. SB203580 blocked jellyfish-HE-induced apoptosis. Additionally, Jellyfish-HE markedly arrests the cell cycle in the G0/G1 phase. Therefore, taken together, the results imply that the anti-cancer activity of Jellyfish-HE may be mediated apoptosis by induction of caspases and activation of MAPK, especially phosphorylation of p38, and cell cycle arrest at the Go/G1 phase in K562 cells.

\section{Introduction}

Jellyfish belong to the phylum Cnidaria; they are lower animals with a non-polyp form. They consist of an umbrella-typed bell and trailing tentacles and are made of gelatin-based compounds. Jellyfish are widely distributed in the world's oceans and are rapidly increasing in population [1]. Evolutionarily, jellyfish can be traced in the seas going back approximately 0.7 billion years [2]; they are the oldest known multi-organ animal [3].

Stinging jellyfish is known to have poisonous venom such as cardiovascular and pore-forming toxins [4-10]. The venom is mainly located in extracts from the tentacles, which are made up of nematocysts and other cell types. Recently, jellyfish have been regarded as a beneficial resource having tumorcytotoxic [11], anti-microbial [12] and anti-oxidative [13] properties. To date, various kinds of jellyfish venoms have been reported to have diverse potential effects in the health science field as novel bioactive therapeutic agents with water-soluble or lipid-soluble compounds [14-21]. For example, a mucin glycoprotein of Nemopilema nomurai is a putative drug candidate [22,23]. Several pharmacological properties including angiotensin-I-converting enzyme inhibitory [24], anti-hypertensive [25], and immune-stimulatory activities [26] have been reported. Green fluorescent protein from the jellyfish 
Aequorea victoria [27] is also a well-known biomarker used in the life sciences.

Chronic myeloid leukemia (CML) is a myeloproliferative tumor, which grows from a malignant myeloid lineage. Philadelphia chromosome translocation between chromosomes 9 and 22 is known to be a causative factor in CML with tyrosine kinase activity [28]. Although CML is treated with gleevec, imatinib mesylate (STI-571) as a tyrosine kinase inhibitor, STI-571-resistant patients have appeared, requiring other drug options. To overcome the drug resistance problem, many studies on CML-targeting drugs have been done by various researchers using natural products and cell-derived compounds [29-34].

Induction of apoptosis, or programmed cell death, is a preferred strategy for bringing about CML regression. Apoptosis is a biological adaptation that maintains homeostasis. Two main apoptotic pathways, extrinsic and intrinsic apoptosis, are known. The extrinsic apoptotic pathway is caused by death receptors (DRs). Apoptosis is induced by DRs that are related to activation of caspase- 8 . The other pathway, the intrinsic pathway, involves the mitochondria [35]. Most chemotherapeutic drugs act via stimulating apoptosis of cancer cells. However, toxicity and resistance lead to failure of chemotherapy in CML patients [36]. For that reason, natural compounds are increasingly considered alternative treatment that has potentials for therapy. The cell cycle is intimately involved with cell proliferation and survival of human cancer cells. In normal cells, the cell cycle regulates cellular division and replication, whereas in cancer cells, cell cycle regulation fails, leading to uncontrolled cell proliferation. Therefore, as an alternative anti-cancer strategy, cyclin dependent kinase (CDK) and cyclin, cell cycle regulators have been considered for patients with CML. Because cells are arrested at cell cycle checkpoints in order to repair cellular damage and control cell cycle-related genes, cell cycle-related therapy is a promising strategy for cancer treatment [37].

We have searched for potential therapeutic agents with effects against CML based on natural compounds, especially from marine sources. In this study, we carried out activity-based pharmacological assays using extracts from Nomura's jellyfish obtained through solvent-based fractionation, and several anti-cancer compounds were obtained from fractionation using extraction with different solvents. Then, 
95 we demonstrated that jellyfish hexane extract has potential anti-cancer activity in K562 cells, as treatment

96 of cells induces apoptosis and cell cycle arrest.

97

98

99

100

101

102

103

104

105

106

107

108

109

110

111

112

113

114

115

116

117

118

Materials and Methods

\section{Extraction of Jellyfish hexane extract (Jellyfish-HE)}

Stomolophus nomurai (Nomura's jellyfish) were harvested from the shore near Busan, Korea. The voucher specimen has been deposited after classical identification in the invertebrate animals stocks of College of Fisheries Sciences, Pukyung National University, Busan, Korea (Prof NG Park). In order to dry the raw materials, the jellyfish has been harvested from coastal fishery and the water content was naturally removed using a house sieve. Then the roughly dried jellyfish (100 g) was vacuum-dried using a freezing dryer (Ilshin Lab Co., LTD, Seoul, Korea). Dried jellyfish (36 g) fragmentized were extracted with $300 \mathrm{ml}$ of $50 \%$ ethanol $(\mathrm{EtOH})$ three times under reflux at $50^{\circ} \mathrm{C}$ for $24 \mathrm{~h}$, then filtered and concentrated to yield the EtOH extract ( $25 \mathrm{~g}$ ). The EtOH extract was suspended in $100 \mathrm{ml} \mathrm{H}_{2} \mathrm{O}$ and extracted successively with n-hexane (Hex), ethylacetate (EtOAc; EA), and n-butanol (n-BuOH) to yield an n-hexane fraction (34 mg), an EA fraction (42 mg), an $\mathrm{n}-\mathrm{BuOH}$ fraction (1.9 g), and water residue (18.4 g). The concentrated extract (34 mg) was then lyophilized, resulting in $14.9 \mathrm{mg}$ of powder. Dried HE was subsequently dissolved in dimethyl sulfoxide (DMSO) diluted with DMEM media. The final concentration of DMSO was adjusted to $0.1 \%(\mathrm{v} / \mathrm{v})$ in the culture media.

\section{Cell culture and reagents}

The human CML K562 cell line, human colon cancer HCT116 cells and human liver cancer Huh-7 cells were purchased from ATCC (American Type Culture Collection) (Rockville, MD, USA). The human CML K562 cell line was cultured in RPMI1640, HCT116 cells and Huh-7 cells were cultured in DMEM (WelGENE Co., Daegu, Korea) containing 10\% fetal bovine serum (FBS), penicillin (100 U/mL), 
119 and streptomycin $(100 \mathrm{mg} / \mathrm{mL})$ at $5 \% \mathrm{CO} 2$ in a humidified incubator at $37 \square$ C. Z-VAD-FMK (a pan-

120 caspase inhibitor) (catalog no. 219007) was purchased from Calbiochem (Darmstadt, Germany). 3-(4,5-

121 dimethylth-iazol-2-yl)-2,5-diphenyltetrazolium bromide (MTT) (catalog no. M2128) was purchased from

122 Sigma-Aldrich (St. Louis, MO, USA). 6-diamidino-2-phenylindole dihydrochloride (DAPI) (catalog no.

123 D9542) was purchased from Sigma-Aldrich (St. Louis, MO, USA). SB203580 (catalog no. 559389) and

124 SP600125 (catalog no. 420119) were purchased from Calbiochem (Darmstadt, Germany). U0126 (catalog

125 no. V1121) was purchased from Promega (Madison, WI, USA). Antibodies against caspase-3 (catalog no.

126 9661), caspase-8 (catalog no. 9746), cleaved caspase-9 (catalog no. 9501), p-JNK (catalog no. 9251),

127 JNK (catalog no. 9252), and p-p38 (catalog no. 9211) were purchased from Cell Signaling Technology

128 (Dancers, MA, USA). Antibodies against $\beta$-actin (catalog no. sc-47778), PARP-1 (catalog no. sc-7150),

129 Bcl-2 (catalog no. sc-492), BAX (catalog no. sc-493), p38 (catalog no. sc-535), CDK2 (catalog no. 163),

130 CDK4 (catalog no. sc-264), cyclin A (catalog no. sc-596), and cyclin D1 (catalog no. sc- 450) were

131 purchased from Santa Cruz Biotechnology (Paso Robles, CA, USA). The Bio-Rad protein assay kit

132 (catalog no. 500-0114 and 500-0113) was purchased from Bio-Rad (Richmond, CA, USA). The Annexin

133 V-FITC/PI apoptosis detection kit (catalog no. 556547) was purchased from BD Biosciences (San Jose, 134 CA, USA).

135

136 MTT assay

137 Cell were plated in a 96-well culture plate $\left(5 \times 10^{4}\right.$ cells/well) and treated with various concentrations $138(0,10,20,30,40$, and $50 \mu \mathrm{g} / \mathrm{ml})$ of Jellyfish-HE. After $24 \mathrm{~h}$, the media was removed and MTT $(0.5$ $139 \mathrm{mg} / \mathrm{ml}$ ) was added to each well for $4 \mathrm{~h}$. Formazan crystals from MTT reduction were dissolved in DMSO 140 and the OD value was read at $590 \mathrm{~nm}$ with a Versamax microplate reader (Molecular Devices, CA, USA). 141

142 DAPI stain assay 
After treatment with Jellyfish-HE, to confirm nuclear condensation, cells were stained with DAPI.

144 Before treatment with Jellyfish-HE, cover slides were coated with lysine to encourage attachment of 145 K562 cells. Cells were spread in 24-well culture plates (4 X $10^{5}$ cells/well) and treated with Jellyfish-HE $146(40 \mu \mathrm{g} / \mathrm{mL})$ for $24 \mathrm{~h}$. Then, cells were washed with 1 X PBS and fixed with $4 \%$ paraformaldehyde. After 14720 mins at $4^{\circ} \mathrm{C}$, the cells were washed with 1 X PBS and stained with DAPI $(1 \mathrm{mg} / \mathrm{mL})$ for 10 mins at 148 room temperature in the dark. Then, the cells were washed with 1 X PBS and mounted with mounting 149 solution (Dako, Glostrup, Denmark). Nuclei were detected under a fluorescence microscope TMS (Nikon, 150 Tokyo, Japan).

\section{Annexin V and PI staining}

After treatment with $40 \mu \mathrm{g} / \mathrm{ml}$ of jellyfish hexane extract for $8 \mathrm{~h}, \mathrm{~K} 562$ cells were harvested and cell were washed with PBS and suspended with binding buffer (1X). After that $4 \mu \mathrm{l}$ Annexin V-FITC and $2 \mu 1$ 155 propidium iodide (PI) were added in the cells for $15 \mathrm{~min}$ at $37{ }^{\circ} \mathrm{C}$ in the dark. Then, cells were analyzed with a flow cytometer, FACS Canto II (BD Biosciences, San Jose, CA, USA). Using this data, Living cells (Annexin V-/PI-), early apoptotic cells (Annexin V+/PI-), late apoptotic cells (Annexin V+/ PI+), necrotic cells (Annexin V-/PI-) cells were measured.

\section{Western blot analysis}

K562 cells were lysed in a buffer containing $50 \mathrm{mmol} / \mathrm{L}$ Tris- $\mathrm{HCl}(\mathrm{pH} 8.0), 150 \mathrm{mmol} / \mathrm{L} \mathrm{NaCl}, 100 \mathrm{~m}$ mol/L NaF, $100 \mathrm{mg} / \mathrm{mL}$ phenylmethylsulfonyl fluoride (PMSF), $1 \mathrm{mg} / \mathrm{mL}$ aprotinin, and 1\% Triton X100. After 30 mins at $4^{\circ} \mathrm{C}$, cells were centrifuged at $13,000 \mathrm{rpm}$ at $4^{\circ} \mathrm{C}$. Then, protein concentration in the supernatant was quantified using the Bio-Rad protein assay (Bio-Rad, Berkeley, CA, USA). Equal amounts of whole cell lysates were fractionated by sodium dodecyl sulfate-polyacrylamide gel 
166

167

168

169

170

171

172

173

174

175

176

177

178

179

180

181

182

183

184

185

186

187

188

electrophoresis (SDS-PAGE). After electrophoresis, gels were transferred to polyvinylidene difluoride (PVDF) membranes using the Hoefer electrotransfer system (Amersham Biosciences, Buckinghamshire, UK). To visualize the target protein, the membranes were incubated at $4^{\circ} \mathrm{C}$ overnight with each primary antibody. Then, the membranes were washed and incubated at room temperature for $1 \mathrm{~h}$ with the appropriate secondary antibody. Detection was carried out using a secondary horseradish peroxidaselinked antibody and the ECL chemiluminescence system (Amersham Biosciences, Buckinghamshire, UK). Films were scanned and densitometry analysis was performed using Image $\mathrm{J}$ software.

\section{Cell cycle analysis}

To analyze cell cycle, K562 cells were treated with $40 \mu \mathrm{g} / \mathrm{ml}$ of Jellyfish-HE for $12 \mathrm{~h}$ and cells were harvested, fixed with $70 \%$ ethanol at $4^{\circ} \mathrm{C}$ for $30 \mathrm{~min}$. Fixed cells were washed with PBS and then stained PI buffer containing propidium iodide, RNase, Nacitrate and NP-40 for $30 \mathrm{~min}$ in the dark. After that cells were analyzed by flow cytometer, FACS Canto II (BD Biosciences, San Jose, CA, USA).

\section{Statistical analysis}

All data are expressed as means \pm SEM of three independent replicates for each group. Comparisons were made by Student's $t$-test. ${ }^{*} \mathrm{P}<0.05$ was considered statistically significant. Statistical analysis was measured using GraphPad Prism software 5.0.

\section{Results}

\section{Jellyfish hexane extract specifically induces cell death in $\mathrm{K562}$ cancer cells.}

In order to examine whether Jellyfish extracts can affect cell viability in the K562 cancer cell line, jellyfish were extracted with a variety of organic solvents $(\mathrm{EtOH}, \mathrm{BuOH}$, Ethyl Acetate, and hexane), as 
189 well as distilled water, as described in the Materials and Methods section. Then, human chronic myeloid

190 leukemia K562 cells were treated for 3 days with $50 \mu \mathrm{g} / \mathrm{ml} \mathrm{EtOH}, \mathrm{BuOH}$, ethyl acetate, or hexane extract.

191 Only Jellyfish-HE obviously exhibited the reduced cell viability at the concentrations used. Cell viability

192 was measured using the MTT assay. As shown in Figure 1, cell viability of K562 cells was specifically

193 decreased in Jellyfish-HE-treated cells. The results demonstrated that Jellyfish-HE specifically decreases

194 cell viability in K562 cells, whereas the other extracts do not.

195

196

197

198

199

200

201

202

203

204

205

206

207

208

209

210

211

212

Furthermore, K562 cells have been treated with the $\mathrm{H} 2 \mathrm{O}$ extracts, EtOH extracts, $\mathrm{BuOH}$ extracts, EA extracts and hexane extracts for 1 to 3 days to evaluate possible changes in acting compounds. The results have also shown that the $\mathrm{H} 2 \mathrm{O}$ extracts, $\mathrm{EtOH}$ extracts, $\mathrm{BuOH}$ extracts and EA extracts do not affect cell viabilities, in contrast to hexane extracts in K562 cells (Supplementary Figure 1). These results indicated that the long term treatment such as 3 days does not seem to cause loss of activity of the active compounds.

\section{Jellyfish hexane extract induces cell death in a dose-dependent manner in various cancer cell lines}

Because Jellyfish-HE inhibits the growth of human chronic myeloid leukemia K562 cells, we investigated its effects in other cancer cell lines. Several cancer cell lines, including human colon cancer HCT116 cells and human liver cancer Huh-7 cells, were treated with Jellyfish-HE and assessed for cytotoxicity. Cells were treated with various concentrations $(0,10,20,30,40$, and $50 \mu \mathrm{g} / \mathrm{ml})$ of JellyfishHE for 24 h, as shown in Figure 2. As shown in Figure 2, the growth rate of HCT116 human colon cancer cells (Figure 2B) and Huh-7 human liver cancer cells (Figure 2C) were examined using an MTT assay. When half-maximal inhibition concentrations (IC50) were measured on the cancer cell lines, each IC50 value was calculated to be $49.51 \mu \mathrm{g} / \mathrm{ml}, 62.85 \mu \mathrm{g} / \mathrm{ml}$ and $67.28 \mu \mathrm{g} / \mathrm{ml}$ for K562 cells, HCT116 cells and Huh-7 cells, respectively (Figure 2). For the calculation of IC50, the computed maximum effects on cell viability were calculated to be $33.85 \%(84.23 \mu \mathrm{g} / \mathrm{ml})$ in $\mathrm{K} 562$ cells, $34.34 \%(101.0 \mu \mathrm{g} / \mathrm{ml})$ in $\mathrm{HCT} 116$ 
213 cells and $39.66 \%(104.9 \mu \mathrm{g} / \mathrm{ml})$ in Huh-7 cells. The results of the MTT assays showed that Jellyfish-HE

214 inhibits cell proliferation in a dose-dependent manner in all cancer cell lines. K562 cells were especially

215 susceptible to Jellyfish-HE-induced growth suppression, although growth of all of the tested cancer cells 216 was inhibited.

Jellyfish hexane extract induces apoptosis characterized by typical biochemical and morphological changes, such as cell shrinkage, DNA fragmentation, chromatin condensation, and formation of apoptotic bodies in $\mathrm{K562}$ cells

Apoptosis is typically characterized by cell death-related biochemical and morphological changes such as cell shrinkage, DNA fragmentation, chromatin condensation, and formation of apoptotic bodies [16]. In this study, to determine whether Jellyfish-HE induces cell death by apoptosis, K562 cells were treated with various concentrations $(0,10,20,30,40$, and $50 \mu \mathrm{g} / \mathrm{ml})$ of Jellyfish-HE for $24 \mathrm{~h}$, and then morphological changes were observed using microscopy. Apoptotic cell body-like cell morphologies were easily observed in Jellyfish-HE-treated K562 cells in a dose-dependent manner (Figure 3A). To further examine the nuclear morphological changes in K562 cells, DAPI staining was performed after treatment with $40 \mu \mathrm{g} / \mathrm{ml}$ Jellyfish-HE (Figure 3B). As shown in Fig. 3B, apoptotic body-like shapes and chromatin condensation were observed in cells treated with $40 \mu \mathrm{g} / \mathrm{ml}$ of Jellyfish-HE compared with untreated control cells. Next, to confirm that Jellyfish-HE-induced apoptosis is directly under the control of Jellyfish-HE, cells were treated with $40 \mu \mathrm{g} / \mathrm{ml}$ Jellyfish-HE for $8 \mathrm{~h}$ and then assessed using Annexin VFITC/PI staining and quantitative analysis (Figure 3C). When the statistical significance has been analyzed using Student's t-test, the Annexin V-positive, PI-positive and Annexin V/PI-double positive cells were significantly increased (Figure 3D). The 3 positive levels are similar to that of the known apoptotic agents such as lactose-binding lectins [29]. The results clearly show that the levels of Annexin $\mathrm{V}$ and Annexin V-PI positive cells were increased by treatment with $40 \mu \mathrm{g} / \mathrm{ml}$ Jellyfish-HE. These results 
Jellyfish hexane extract-mediated apoptosis acts through the intrinsic and extrinsic apoptotic pathways in $\mathrm{K562}$ cells

Caspases are vital in apoptosis. Therefore, after treatment of K562 cells with $40 \mu \mathrm{g} / \mathrm{ml}$ Jellyfish-HE,

242

243

244

245

246

247

248

249

250

251

252

253

254

255

256

257

258

259

260

the cleaved forms of PARP and procaspase- 3 through activation of caspase- 8 and caspase- 9 were investigated by immunoblotting analysis and densitometry. Cleaved PARP and mature caspase-3 levels were normalized to those of $\beta$-actin as an internal control (Figure $4 \mathrm{~A}, \mathrm{~B}$ ). The results demonstrated that Jellyfish-HE induces apoptosis in a dose-dependent manner through both the extrinsic and intrinsic apoptotic pathways in K562 cells. The BCL-2 family is a group of proteins that have both pro- (BAX, BAD, and others) and anti- (BCL-2, Bcl-xL, and others) apoptotic functions. Thus, the relative ratio of those proteins expressed during the apoptotic process helps to determine the type of cell death signaling [38]. As shown in Figure 4C and D, after treatment with $40 \mu \mathrm{g} / \mathrm{ml}$ Jellyfish-HE for $24 \mathrm{~h}$, the levels of BCL-2 and BAX were analyzed by immunoblotting and densitometry. The level of BCL-2 was decreased, while that of BAX was slightly increased and the ratio of BAX/BCL-2 was significantly increased. To further confirm that Jellyfish-HE induces apoptosis that depends on the caspase cascade, K562 cells were treated with a pan-caspase inhibitor, Z-VAD, along with $40 \mu \mathrm{g} / \mathrm{ml}$ Jellyfish-HE for $12 \mathrm{~h}$, and cell viability was measured with the MTT assay (Figure 4E). In the same conditions as shown in Fig. 4E, the levels of PARP and caspase-3 were also analyzed by immunoblotting (Figure 4F). Treatment with Z-VAD and Jellyfish-HE resulted in an increase in the viability of K562 cells compared to cells incubated in the absence of Z-VAD and the presence of Jellyfish-HE. Likewise, the levels of cleaved caspase-3 and PARP were increased in the presence of Z-VAD and Jellyfish-HE in K562 cells. Overall, these results suggest that Jellyfish-HE induces caspase-dependent apoptosis through both the extrinsic and intrinsic apoptotic pathways. 
262

263

264

265

266

267

268

269

270

271

272

273

274

275

276

277

278

279

280

281

282

283

284

285

286

\title{
Jellyfish hexane extract induces apoptosis through the p38 pathway.
}

\author{
In caspase-regulated apoptotic cell death, the MAPK signaling pathway, which involves ERK1/2,
} p38, and JNK, has been reported to play important roles, and it controls apoptosis in human cancers [39].

In the present study, in order to examine whether the MAPK signaling pathway activates Jellyfish-HEinduced apoptosis, we analyzed the phosphorylation level of MAPK by Western blot analysis after treatment of K562 cells with $40 \mu \mathrm{g} / \mathrm{ml}$ of Jellyfish-HE for various times up to $2 \mathrm{~h}$ and in different doses for $12 \mathrm{~h}$. As shown in Figure 5A and 5C, the levels of phosphorylated ERK, phosphorylated JNK, and phosphorylated p38 were significantly increased in dose- and time-dependent manners, while the total levels of such proteins remained unchanged, indicating increased phosphorylation of the signaling molecules. To compare the relative ratio between the phosphorylated forms and total protein forms, each was analyzed by densitometry using Image $\mathrm{J}$ software (Figure $5 \mathrm{~B}, \mathrm{D}$ ). Although the three different MAPKs, ERK, JNK, and p38, were all activated by Jellyfish-HE, a more precise role of each one may be important in the subsequent process of apoptosis. Therefore, to confirm which MAPK affects JellyfishHE-induced apoptosis, K562 cells were examined using specific inhibitors of MAPK signaling. Cells were pretreated for $1 \mathrm{~h}$ with $10 \mu \mathrm{M}$ of specific inhibitors, U0126 (ERK inhibitor), SP600125 (JNK inhibitor), and SB203580 (p38 inhibitor), and then treated with $40 \mu \mathrm{g} / \mathrm{ml}$ of Jellyfish-HE for a further 12 h. The viability of the treated cells was then measured using the MTT assay. Treatment of the cells with Jellyfish-HE and SB203580 resulted in a slight increase in cell viability compared with treatment with Jellyfish-HE only (Figure 5E). In contrast, treatment with U0126 or SP60015 failed to inhibit JellyfishHE-induced apoptosis (supplementary Figure 2). To further investigate the mechanisms of apoptosis, we analyzed the expression levels of apoptotic proteins, which are specifically related to the biochemical and enzymatic processes, by Western blotting. As shown in Figure 5F, the level of cleaved caspase-3 (detected at $17 \mathrm{kD}$ and $19 \mathrm{kD}$ ), a well-known indicator of apoptosis, is decreased when $10 \mu \mathrm{M}$ of SB203580 was applied for $1 \mathrm{~h}$ followed by $40 \mu \mathrm{g} / \mathrm{ml}$ of Jellyfish-HE treatment for $12 \mathrm{~h}$. These results indicated that p38 MAPK signaling is directly related to Jellyfish-HE-induced apoptosis in K562 cells. 
Jellyfish hexane extract induces cell cycle arrest

289

290

291

292

293

294

295

296

297

298

299

300

301

302

303

304

305

306

307

308

309

310

As shown in Fig. 1, Jellyfish-HE decreased the growth rate of K562 cells. Therefore, we investigated whether the Jellyfish-HE extract affects cell cycle. K562 cells were treated with $40 \mu \mathrm{g} / \mathrm{ml}$ of Jellyfish-HE or absence of Jellyfish-HE for 12h. Jellyfish-HE treated K562 cells were arrested in G0/G1phase (Figure 6A and B). To further investigate, whether the cell cycle-related proteins CDK2, CDK4, cyclin A, and cyclin D1 are altered in Jellyfish-HE-treated cells. K562 cells were treated with various concentrations $(0$, $10,20,30$, and $40 \mu \mathrm{g} / \mathrm{ml}$ ) of Jellyfish-HE for $24 \mathrm{~h}$ and cell extracts were subjected to immunoblotting and densitometry analysis. Cyclin D1 and CDK4 are known to be expressed in the initial stages of the G1 and S1 phase transitions [40]. Therefore, downregulation of Cyclin D1 and CDK4 is regarded as an indicator of G0/G1 cell cycle arrest. In this study, as shown in Figure 6C, treatment of the cells with various concentrations of Jellyfish-HE significantly decreased the expression levels of the G0/G1 cell cyclerelated proteins Cyclin D1 and CDK4 in a dose-dependent manner. Other proteins involved in the cell cycle, CDK2 and cyclin A, were also downregulated by Jellyfish-HE treatment (Figure 6D). Although the expression levels of CDK2, CDK4, and Cyclin D1 proteins were up-regulated by HE extract treatment at low dose $(10 \mu \mathrm{g} / \mathrm{ml})$, the adaptation state of the cells is suggested. In general, most cells respond to environmental changes such as stress, which called "Adaptation" for cell survival, as previously reported [41]. However, high doses of Jellyfish-HE directly induce cell injury, cell death and cell cycle arrest. These results show that Jellyfish-HE induces G0/G1 cell cycle arrest that is regulated by cell cycle-related proteins in K562 cells.

\section{Discussion}

Jellyfish is well known as a marine animal with venomous tentacles. However, the detailed compounds and structure-based molecular targets in hosts responsible for the toxic effects of jellyfish 
311 venom are unknown [4]. Recently, jellyfish have become a worldwide ecological problem as their

312 population is growing rapidly. An innovative system for jellyfish disposal has not been developed.

313 Recently, several pharmacological activities have been reported from the Jellyfish [11, 12, 13] and thus,

314 we have investigated the anti-cancer activities of jellyfish extracts against human chronic myeloid

315 leukemic cells. In our investigation into CML-specific drugs, we have found that jellyfish hexane extract

316 induces cell death through apoptosis and cell cycle arrest in K562 CML cells. The mechanism of action of

317 jellyfish hexane extract, induction of apoptosis, was studied with pharmaceutical applications in mind.

318 In the present study, with an eye towards developing alternative treatments using natural products

319 [42], we investigated the anti-cancer effect of Jellyfish-HE on apoptosis and cell cycle arrest. Apoptosis is

320 a mode of programmed cell death that regulates cellular function for organismal homeostasis, survival,

321 and cell death [43]. After treatment with Jellyfish-HE, apoptotic cell bodies (Figure 2A) and nuclear

322 condensation, which are characteristic of apoptosis, were observed in K562 cells. Furthermore, caspases

323 are important proteins for controlling cell death and inflammation. In this study, caspase-3 and PARP

324 were detected as markers of apoptosis (Figure 3B). Caspase-3 and PARP are cleaved by activated

325 apoptotic caspases [44]. When K562 cells were treated with Jellyfish-HE, we observed activation of

326 caspase-3 and PARP in a dose-dependent manner. Moreover, when a pan-caspase inhibitor, Z-VAD, was

327 applied before Jellyfish-HE, we observed an increase in cell viability as well as inhibition of cleaved

328 PARP and caspase-3. Cleavage of caspase-3 and PARP are well known as classic apoptosis markers in

329 many cancer cells [33,35], and two pathways, the extrinsic and the intrinsic pathway, are involved. The

330 extrinsic apoptotic pathway, which is caused by DRs, is regulated by caspase-8, while intrinsic apoptosis,

331 which involves the mitochondria, is associated with activated caspase-9 and activated caspase-3, which is

332 cleaved by caspase- 8 and caspase-9 [45]. Treatment with Jellyfish-HE induced activation of caspase-8

333 and caspase-9 (Figure 3A and B), implying that Jellyfish-HE induces apoptosis via both the intrinsic and

334 extrinsic apoptotic pathways. However, how Jellyfish-HE induces the extrinsic apoptotic pathway is

335 unclear. Interestingly, our results showed decreased Bcl-2 and increased BAX protein expression (Figure

336 3C). Based on the $\mathrm{BAX} / \mathrm{Bcl}-2$ ratio, we demonstrated that Jellyfish-HE induces the intrinsic apoptosis 
337 pathway in the K562 cell line (Figure 3D). Thus, the intrinsic apoptosis pathway, mediated by the Bcl-2 338 family, including Bcl-2 and BAX, is affected by Jellyfish-HE. Bcl-2 was initially discovered in B cell 339 lymphoma. The Bcl-2 family regulates both anti-apoptotic and pro-apoptotic proteins and is correlated 340 with the activity of mitochondria. Bcl-2 is an anti-apoptotic protein that regulates calcium homeostasis.

341 BAX, on the other hand, is a well-known pro-apoptotic protein that stimulates release of cytochrome C $342[46]$.

MAPK family members also have important role in apoptosis. MAPKs include ERKs, c-JNKs, and p38 kinase. Typically, JNK and p38 kinase are known as cell death signals, whereas ERK is a survival signal [47]. However, it has been demonstrated that ERK is involved in both cell survival and cell death in some conditions. Namely, phosphorylated ERK has been associated with apoptosis [48]. In the present paper, after treatment with Jellyfish-HE, cells demonstrated an upregulation in phosphorylated ERK, JNK, and p38 kinase in time- and dose-dependent manners. However, treatment with specific MAPK inhibitors along with Jellyfish-HE in K562 cells did not block apoptosis, except for an inhibitor of p38 kinase (Figure 5A and B). Thus, we suggest that p38 kinase is specifically related to Jellyfish-HE-induced apoptosis in K562 cells (Figure 5 E and F). Our results also clearly showed that Jellyfish-HE alters cell cycle-related proteins; it induces decreases in CDK2, CDK4, Cyclin A and Cyclin D1 levels in K562 cells (Figure 6C and D). Thus, we suggest that Jellyfish-HE induces cell cycle arrest by reducing the levels of CDK2, CDK4, Cyclin A, and Cyclin D1. However its exact mechanism of action is not clear. To date, several approaches have been tried to treat the patients even without complete efficacy. For the successful cases, several CML-therapeutic drugs including imatinib (known as Glivec) [49], dasatinib [50] and nilotinib [51] have been clinically treated. However, such effective drugs are recently suffered from the occurrence of the unknown drug resistances in the patients [52]. Therefore, chemotherapeutic drugs against CML have been subjected to search from the natural resources [53]. In conclusion, Jellyfish-HE is a potential novel cancer therapy for CML which induces apoptosis and cell cycle arrest. As shown in

361 Figure 7, although jellyfish is a stinging organism and its known toxic compounds are reported to be 
362

363

364

365

366

367

368

369

370

371

372

373

374

375

376

377

378

379

380

381

382

water-soluble polypeptides, the present results clearly suggest that Jellyfish-HE contains valuable compounds that can target cancer cells, such as malignant leukemic cells.

\section{References}

1. Lucas Brotz, William W. L. Cheung, Kristin Kleisner, Evgeny Pakhomov, Daniel Pauly; Increasing jellyfish populations: trends in Large Marine Ecosystems. Hydrobiologia 2012, 690:3-20

2. Cartwright P, Halgedahl SL, Hendricks JR, Jarrard RD, Marques AC, Collins AG, Lieberman BS; Exceptionally preserved jellyfishes from the Middle Cambrian. PLoS One. 2007

3. Jump up to: a b c d ANGIER, NATALIE (June 6, 2011). "So Much More Than Plasma and Poison". The New York Times. Retrieved 2 December 2011.

4. Li R, Yu H, Xue W, Yue Y, Liu S, Xing R, Li P; Jellyfish venomics and venom gland transcriptomics analysis of Stomolophus meleagris to reveal the toxins associated with sting. J. Proteomics. 2014 Jun $25 ; 106: 17-29$.

5. Burnett, J.W. Treatment of Atlantic cnidarian envenomations. Toxicon 2009, 54, 1201-1205.

6. Yanagihara, A.A.; Shohet, R.V. Cubozoan venom-induced cardiovascular collapse is caused by hyperkalemia and prevented by zinc gluconate in mice. PLoS One 2012, 7, e51368.

7. Tibballs, J.; Yanagihara, A.A.; Turner, H.C.; Winkel, K. Immunological and toxinological responses to jellyfish stings. Inflamm. Allergy Drug Targets 2011, 10, 438-446.

8. Marino, A.; Crupi, R.; Rizzo, G.; Morabito, R.; Musci, G.; La Spada, G. The unusual toxicity and stability properties of crude venom from isolated nematocysts of Pelagia noctiluca (Cnidaria, Scyphozoa). Mol. Cell. Biol. 2007, 53, OL994-OL1002. 
383 9. Mariottini GL; Hemolytic venoms from marine cnidarian jellyfish - an overview. J Venom Res. 2014 384 Jul 23;5:22-32

385 10. Jennifer E. Purcell, Shin-ichi Uye, Wen-Tseng Lo; Anthropogenic causes of jellyfish blooms and their 386 direct consequences for humans: a review. Mar Ecol Prog Ser. 2007, 350: 153-174,

387 11. Kang C, Munawir A, Cha M, Sohn ET, Lee H, Kim JS, Yoon WD, Lim D, Kim E; Cytotoxicity and 388 hemolytic activity of jellyfish Nemopilema nomurai (Scyphozoa: Rhizostomeae) venom. Comp Biochem 389 Physiol C Toxicol Pharmacol. 2009, 150(1):85-90.

390 12. Ovchinnikova TV, Balandin SV, Aleshina GM, Tagaev AA, Leonova YF, Krasnodembsky ED, 391 Men'shenin AV, Kokryakov VN; Aurelin, a novel antimicrobial peptide from jellyfish Aurelia aurita with 392 structural features of defensins and channel-blocking toxins. Biochem Biophys Res Commun. 2006, 393 22;348(2):514-23;

394 13. Yu H, Liu X, Xing R, Liu S, Li C, Li P; Radical scavenging activity of protein from tentacles of 395 jellyfish Rhopilema esculentum. Bioorg Med Chem Lett, 2005, 16;15(10):2659-64. ;

14. Leone A, Lecci RM, Durante M, Piraino S.; Extract from the Zooxanthellate Jellyfish Cotylorhiza tuberculate Modulates Gap Junction Intercellular Communication in Human Cell Cultures. Mar. Drugs 398 $2013,11,1728-1762$

15. Rocha, J.; Peixe, L.; Gomes, N.C.; Calado, R. Cnidarians as a source of new marine bioactive compounds-an overview of the last decade and future steps for bioprospecting. Mar. Drugs 2011,

9, 1860-1886. $2003,8,536-544$. 
405 clinical trials. Expert Opin. Investig. Drugs 2003, 12, 1367-1383.

406 18. Mariottini, G.L.; Pane, L. The role of Cnidaria in drug discovery. A review on CNS implications

407 and new perspectives. Recent Pat. CNS Drug Discov. 2013, 8, 110-122.

408 19. Morabito, R.; La Spada, G.; Crupi, R.; Esposito, E.; Marino, A. Crude venom from nematocysts

409 of the jellyfish Pelagia noctiluca as a tool to study cell physiology. Cent. Nerv. Syst. Agents

410 Med. Chem. 2015, 15:68-73.

411 20. Yanagihara, A.A.; Shohet, R.V. Cubozoan venom-induced cardiovascular collapse is caused by 412 hyperkalemia and prevented by zinc gluconate in mice. PLoS One 2012, 7, e51368.

413 21. Tibballs, J.; Yanagihara, A.A.; Turner, H.C.; Winkel, K. Immunological and toxinological responses 414 to jellyfish stings. Inflamm. Allergy Drug Targets 2011, 10, 438-446..

415 22. Masuda A, Baba T, Dohmae N, Yamamura M, Wada H, Ushida K; Mucin (Qniumucin), a 416 glycoprotein from jellyfish, and determination of its main chain structure. J Nat Prod 2007, 70:1089-1092

417 23. Ohta N, Sato M, Ushida K, Kokubo M, Baba T, Taniguchi K, Urai M, Kihira K, Mochida J; Jellyfish 418 mucin may have potential disease-modifying effects on osteoarthritis. BMC Biotechnol 2009, 9:1-11

419 24. Zhuang Y, Sun L, Li B; Production of the angiotensin-Iconverting enzyme (ACE)-inhibitory peptide 420 from hydrolysates of jellyfish (Rhopilema esculentum) collagen. Food Bioprocess Technol 2010, 5:1622$421 \quad 1629$

25. Zhuang Y, Sun L, Zhang Y, Liu G; Antihypertensive effect of long-term oral administration of 423 jellyfish (Rhopilema esculentum) collagen peptides on renovascular hypertension. Mar Drugs 2012, $424 \quad 10: 417-426$

425 26. Morishige H, Sugahara T, Nishimoto S, Muranaka A, Ohno F, Shiraishi R, Doi M; 426 Immunostimulatory effects of collagen from jellyfish in vivo. Cytotechnology 2011, 63:481-492 
427 27. Shimomura O; Structure of the chromophore of Aequorea green fluorescent protein. FEBS Lett 1979, $428 \quad 104: 220-222$

429 28. Jabbour E, Kantarjian H.; Chronic myeloid leukemia: 2014 update on diagnosis, monitoring, and 430 management. Am J Hematol. 2014, 89(5):547-56

431 29. Kwak CH, Lee SH, Lee SK, Ha SH, Suh SJ, Kwon KM, Chung TW, Ha KT, Chang YC, Lee YC, 432 Kim DS, Chang HW, Kim CH. Induction of Apoptosis and Antitumor Activity of Eel Skin Mucus, 433 Containing Lactose-Binding Molecules, on Human Leukemic K562 Cells. Mar Drugs. 2015 Jun 434 19;13(6):3936-49. doi: 10.3390/md13063936.

435 30. Jin UH, Chung TW, Song KH, Kwak CH, Choi HJ, Ha KT, Chang YC, Lee YC, Kim CH. 436 Ganglioside GM3 is required for caffeic acid phenethyl ester-induced megakaryocytic differentiation of 437 human chronic myelogenous leukemia K562 cells. Biochem Cell Biol. 2014 Aug;92(4):243-9. doi: 438 10.1139/bcb-2014-0015. Epub 2014 May 13.

439 31. Kang SK, Kim YS, Kong YJ, Song KH, Chang YC, Park YG, Ko JH, Lee YC, Kim CH. 440 Disialoganglioside GD3 synthase expression recruits membrane transglutaminase 2 during erythroid 441 differentiation of the human chronic myelogenous leukemia K562 cells. Proteomics. 2008 442 Aug;8(16):3317-28. doi: 10.1002/pmic.200800153.

443 32. Jin UH, Song KH, Motomura M, Suzuki I, Gu YH, Kang YJ, Moon TC, Kim CH.Caffeic acid 444 phenethyl ester induces mitochondria-mediated apoptosis in human myeloid leukemia U937 cells. Mol 445 Cell Biochem. 2008 Mar;310(1-2):43-8. Epub 2007 Nov 30.

446 33. Motomura M, Kwon KM, Suh SJ, Lee YC, Kim YK, Lee IS, Kim MS, Kwon DY, Suzuki I, Kim CH. 447 Propolis induces cell cycle arrest and apoptosis in human leukemic U937 cells through Bcl-2/Bax 448 regulation. Environ Toxicol Pharmacol. 2008 Jul;26(1):61-7. doi: 10.1016/j.etap.2008.01.008

449 34. Jin UH, Ha KT, Kim KW, Chang YC, Lee YC, Ko JH, Kim CH. Membrane type sialidase inhibits the 
450 megakaryocytic differentiation of human leukemia K562 cells. Biochim Biophys Acta. 2008

451 May;1780(5):757-63. doi: 10.1016/j.bbagen.2008.01.019.

452 35. Ola MS, Nawaz M, Ahsan H; Role of Bcl-2 family proteins and caspases in the regulation of 453 apoptosis. Mol Cell Biochem. 2011 May;351(1-2):41-58.

454 36. Ghasemian M, Mahdavi M, Zare P, Ali Hosseinpour Feizi M.; Spiroquinazolinone-induced 455 cytotoxicity and apoptosis in K562 human leukemia cells: alteration in expression levels of Bcl-2 and Bax. 456 J Toxicol Sci. 2015 Feb;40(1):115-26

457 37. Senderowicz AM.; The cell cycle as a target for cancer therapy: basic and clinical findings with the 458 small molecule inhibitors flavopiridol and UCN-01. Oncologist. 2002;7 Suppl 3:12-9

459 38. Gross A, McDonnell JM, Korsmeyer SJ.; BCL-2 family members and the mitochondria in apoptosis. 460 Genes Dev. 1999 Aug 1;13(15):1899-911.

39. Zhang H, Tan S, Wang J, Chen S, Quan J, Xian J, Zhang Ss, He J, Zhang L; Musashi2 modulates K562 leukemic cell proliferation and apoptosis involving the MAPK pathway. Exp Cell Res. 2014 Jan $463 \quad 1 ; 320(1): 119-27$.

40. Liu B, Zhou Z, Zhou W, Liu J, Zhang Q, Xia J, Liu J, Chen N, Li M, Zhu R.; Resveratrol inhibits 465 proliferation in human colorectal carcinoma cells by inducing G1/S-phase cell cycle arrest and apoptosis 466 through caspase/cyclin-CDK pathways. Mol Med Rep. 2014 Oct;10(4):1697-702 Wiley Interdiscip Rev Syst Biol Med. 2011 Sep-Oct;3(5):544-61

42. Lucas DM, Still PC, Pérez LB, Grever MR, Kinghorn AD.; Potential of plant-derived natural products 470 in the treatment of leukemia and lymphoma. Curr Drug Targets. 2010 Jul;11(7):812-22.

471 43. Elmore S.; Apoptosis: a review of programmed cell death. Toxicol Pathol. 2007 Jun;35(4):495-516. 
472

473

474

475

476

477

478

479

480

481

482

483

484

485

486

487

488

489

490

491

492

493

494

44. Ouyang L, Shi Z, Zhao S, Wang FT, Zhou TT, Liu B, Bao JK; Programmed cell death pathways in cancer: a review of apoptosis, autophagy and programmed necrosis. Cell Prolif. 2012 Dec;45(6):487-98.

45. McIlwain DR, Berger T, Mak TW.; Caspase functions in cell death and disease. Cold Spring Harb Perspect Biol. 2013 Apr 1;5(4):a008656.

46. Danial NN.; BCL-2 family proteins: critical checkpoints of apoptotic cell death. Clin Cancer Res. 2007 Dec 15;13(24):7254-63.

47. Osaki LH, Gama P.; MAPKs and signal transduction in the control of gastrointestinal epithelial cell proliferation and differentiation. Int J Mol Sci. 2013 May 13;14(5):10143-61.

48. Cagnol S, Chambard JC.; ERK and cell death: mechanisms of ERK-induced cell death--apoptosis, autophagy and senescence. FEBS J. 2010 Jan;277(1):2-21.

49. Henkes M, van der Kuip H, Aulitzky WE; Therapeutic options for chronic myeloid leukemia: focus on imatinib (Glivec, Gleevectrade mark). Ther Clin Risk Manag. 2008 Feb;4(1):163-87.

50. Hochhaus A, Kantarjian H.; The development of dasatinib as a treatment for chronic myeloid leukemia (CML): from initial studies to application in newly diagnosed patients. J Cancer Res Clin Oncol. 2013 Dec;139(12):1971-84. doi: 10.1007/s00432-013-1488-z. Epub 2013 Aug 13.

51. Saglio G, Kim DW, Issaragrisil S, le Coutre P, Etienne G, Lobo C, Pasquini R, Clark RE, Hochhaus A, Hughes TP, Gallagher N, Hoenekopp A, Dong M, Haque A, Larson RA, Kantarjian HM; Nilotinib versus imatinib for newly diagnosed chronic myeloid leukemia. N Engl J Med. 2010 Jun 17;362(24):2251-9. doi: 10.1056/NEJMoa0912614. Epub 2010 Jun 5.

52. Gómez-Almaguer D, Cantú-Rodríguez OG, Gutiérrez-Aguirre CH, Ruiz-Argüelles GJ; The treatment of CML at an environment with limited resources. Hematology. 2016 May 24:1-7. [Epub ahead of print]

53. Kim C. Preface of the thematic issue of myeloid leukemia. Current Pharmaceutical Biotechnology 2016, 17(1): 2-3. 


\section{Legends}

497 Figure 1. Effects of various jellyfish extracts on K562 cells. (A) K562 cells were treated with $50 \mu \mathrm{g} / \mathrm{ml}$ of medium (negative control), $\mathrm{H}_{2} \mathrm{O}$ extract, EtOH extract, $\mathrm{BuOH}$ extract, EA extract, hexane extract, or DMSO (negative control) for 3 days and cell viability was measured using the MTT assay. *, $\mathrm{P}<0.05$, **, $\mathrm{P}<0.01$ and ***, $\mathrm{P}<0.005$ vs. control (DMSO-treated cells).

501

502

503

504

505

506

507

508

Figure 2. Effects of jellyfish hexane extract on various cancer cell lines, including K562 cells, human colon cancer HCT116 cells, and human liver cancer Huh-7 cells. (A) K562, (B) HCT116, and (C) Huh-7 cell (C) lines were treated with Jellyfish hexane extract for $24 \mathrm{~h}$ and cell viability was measured with the MTT assay. ${ }^{*} \mathrm{P}<0.05,{ }^{*} \mathrm{P}<0.005$ and $* * * \mathrm{P}<0.0005$ vs. control (untreated).

Figure 3. Jellyfish hexane extract induces apoptosis in K562 cells. (A) Morphology. K562 cells were treated for $24 \mathrm{~h}$ with various concentrations of Jellyfish-HE. Phase contrast microscopic observation was been made using a Nikon TMS (Tokyo, Japan). Arrows indicate apoptotic bodies, which are characteristic of cell death. After $24 \mathrm{~h}$ incubation with or without Jellyfish-HE, nuclear fragmentation was stained by DAPI for $10 \mathrm{~min}$ at $37^{\circ} \mathrm{C}$ by fluorescence microscopy (Zeiss Axioskop 2 microscope) (B). Arrows indicate fragmented nuclei. To observe apoptotic cell death in the earlier stages of treatment with Jellyfish-HE, cells were treated with Jellyfish-HE for $8 \mathrm{~h}$. Then, apoptotic cells were detected by PI and Annexin V double staining by flow cytometry (FACS Canto II) (C) and quantitative analysis (D). * $\mathrm{P}<$ $0.05, * * \mathrm{P}<0.005$ and $* * * \mathrm{P}<0.0005$ vs. control (untreated).

Figure 4. Jellyfish hexane extract induces apoptosis via extrinsic and intrinsic pathways in K562 cells. (A) After treatment of K562 cells with various concentrations $(0,10,20,30$, and $40 \mu \mathrm{g} / \mathrm{ml})$ of Jellyfish-HE for $24 \mathrm{~h}$, the expression levels of PARP, caspase- 3 , caspase- 8 and caspase- 9 were analyzed by immunoblotting with antibodies specific for PARP, caspase-3, caspase-8, and caspase-9. (B) The ratio of each protein to $\beta$-actin was calculated using Image $J$ software. (C) After treatment with Jellyfish-HE at 
519 various concentrations for $24 \mathrm{~h}$, levels of Bcl-2 and BAX proteins were analyzed by immunoblotting and

520 the BAX/Bcl-2 ratio was quantified by densitometry (D). K562 cells were treated with $40 \mu \mathrm{g} / \mathrm{ml}$ Jellyfish-

$521 \mathrm{HE}$ for $12 \mathrm{~h}$ in the presence or absence of Z-VAD and then (E) cell viability was measured by an MTT

522 assay and analyzed by immunoblotting (F) with antibodies specific for PARP and capase-3. $\beta$-Actin was

523 used as a loading control. ${ }^{*} \mathrm{P}<0.05,{ }^{* *} \mathrm{P}<0.005$ and ${ }^{* * *} \mathrm{P}<0.0005$ vs. control (untreated). \# $\mathrm{P}<0.05$ vs.

524 treatment with Jellyfish-HE.

525 Figure 5. Jellyfish hexane extract induces apoptosis through the p38 MAPK pathway. pERK1/2, ERK,

526 pJNK, JNK, p-p38, and p38 were specifically detected by immunoblotting analysis at time intervals of 0 ,

$5270.25,0.5,1,1.5$, and $2 \mathrm{~h}$ after treatment with $40 \mu \mathrm{g} / \mathrm{ml}$ Jellyfish-HE (A). After treatment with various

528 concentrations $(0,10,20,30$, and $40 \mu \mathrm{g} / \mathrm{ml})$ of Jellyfish-HE for $12 \mathrm{~h}(\mathrm{C})$, cell extracts were prepared and

529 separated on SDS-PAGE followed by Western blot analysis. Band densities were then analyzed by

530 densitometry using Image $\mathrm{J}$ software (B) and (D). After treatment of the cells with $40 \mu \mathrm{g} / \mathrm{ml}$ Jellyfish-HE

531 in the presence or absence of p38 inhibitor, SB203580, cell viability was measured by the MTT assay (E)

532 and the levels of p-p38, pro caspase-3, and cleaved caspase-3 were specifically detected using Western

533 blots with antibodies specific to p-p38 and caspase-3 (F). $\beta$-Actin was used as an internal control. * $\mathrm{P}<$

$5340.05, * * \mathrm{P}<0.005$ and $* * * \mathrm{P}<0.0005$ vs. control (untreated). \#\# $\mathrm{P}<0.005$ vs. treatment with Jellyfish-HE.

535 Figure 6. Jellyfish hexane extract induces cell cycle arrest. (A) After treatment of cells with or without 40

$536 \mu \mathrm{g} / \mathrm{ml}$ Jellyfish-HE, DNA contents were analyzed by flow cytometer, FACS Canto II. (B) Analysis of cell

537 distribution was quantified using Graph Pad Prism software 5.0. (C) After treatment of cells with various

538 concentrations $(0,10,20,30$, and $40 \mu \mathrm{g} / \mathrm{ml})$ of Jellyfish-HE for $24 \mathrm{~h}$, the cells were analyzed by

539 immunoblotting with antibodies for CDK2, CDK4, Cyclin A, and cyclin D1. $\beta$-Actin was used as a

540 loading control. (D) Band intensities were quantified using Image $\mathrm{J}$ software. $* \mathrm{P}<0.05$ and $* * \mathrm{P}<0.005$

541 vs. control (untreated).

542 Figure 7. Jellyfish hexane extract induces apoptosis through the p38 pathway and cell cycle arrest. Note 
543 that small colorful dots, blue lighting, black arrows and black hammer-head line represent the Jellyfish

544 hexane extract, Jellyfish hexane extract-induced stimulus, direct reactions and each inhibiting reaction, 545 respectively.

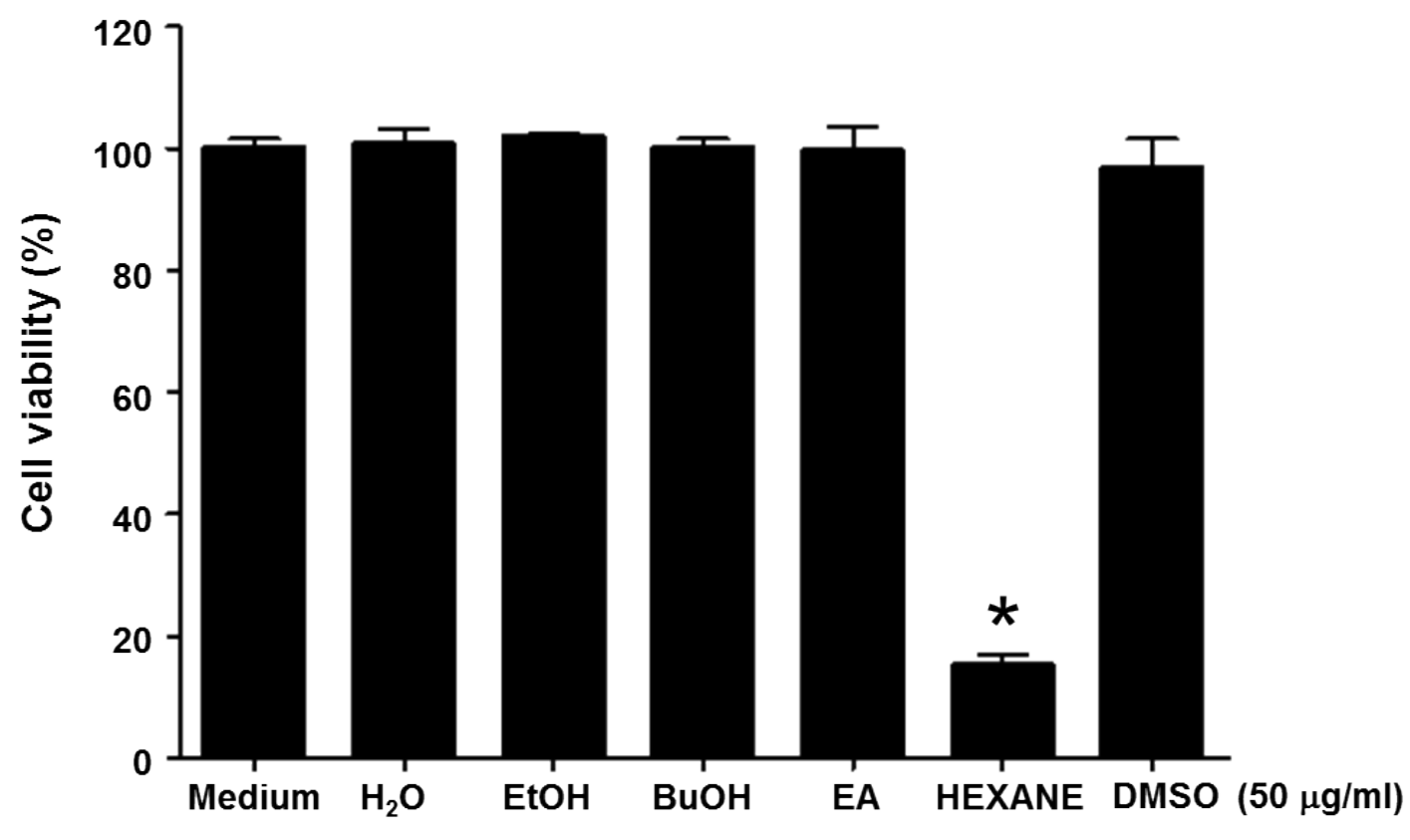

$547 \quad$ Figure 1.

548

A)

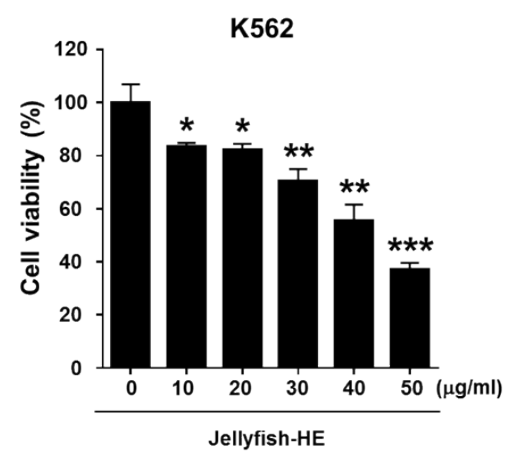

B)

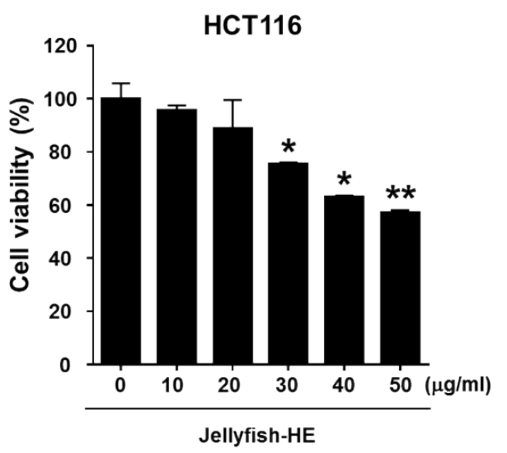

C)

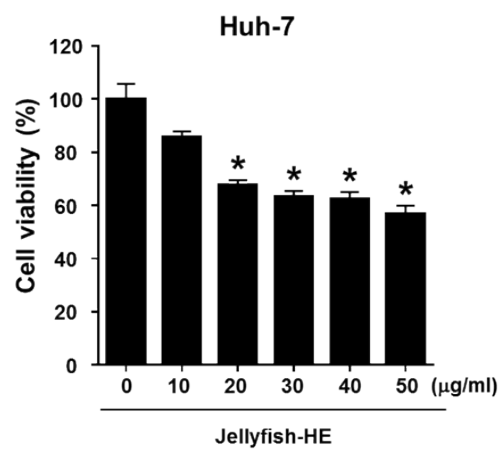

Figure 2. 


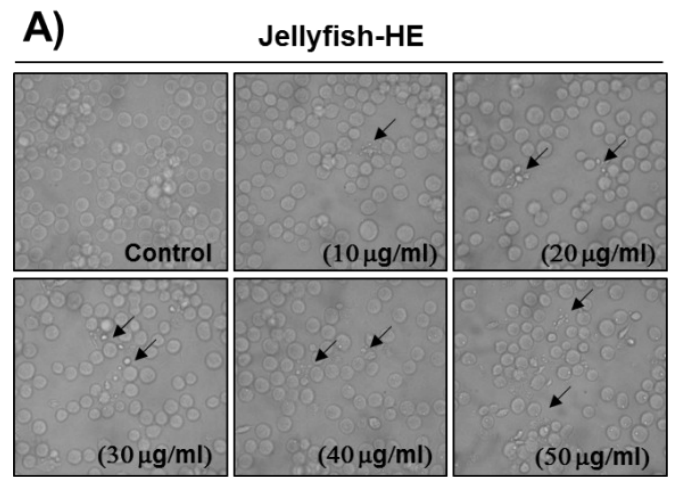

B)
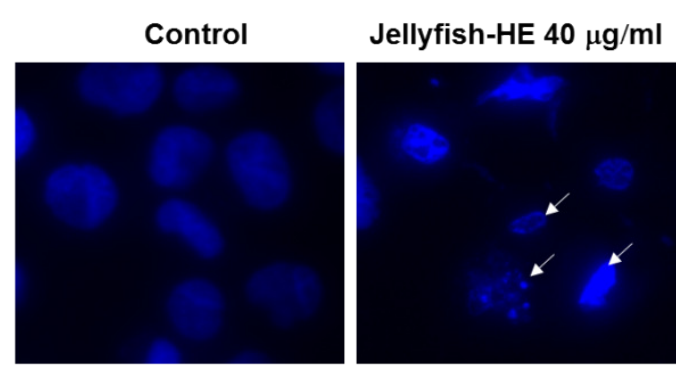

C)

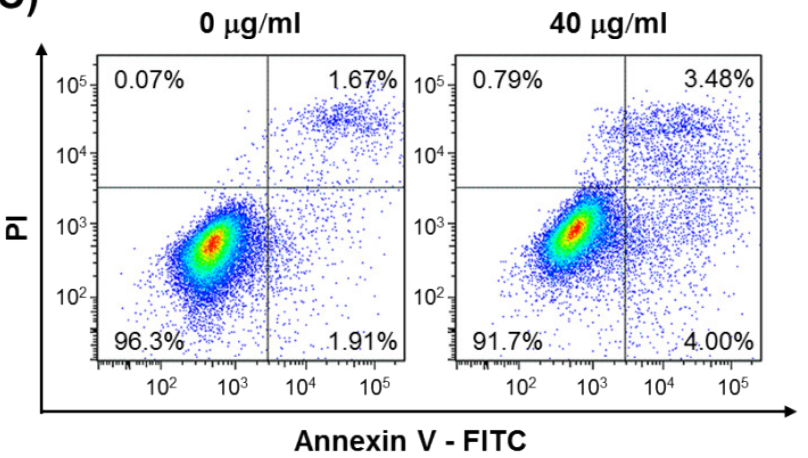

D)

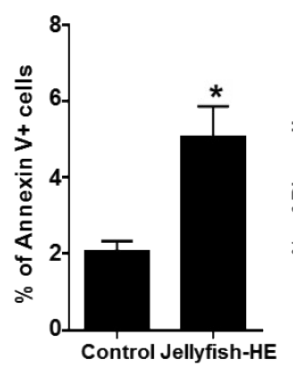

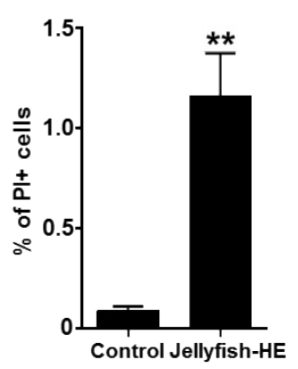

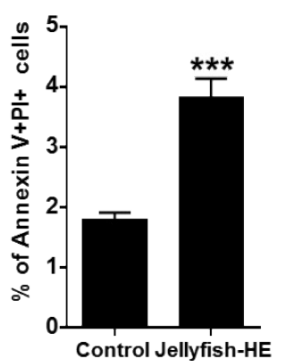

554

555

Figure 3.

556

557

558 


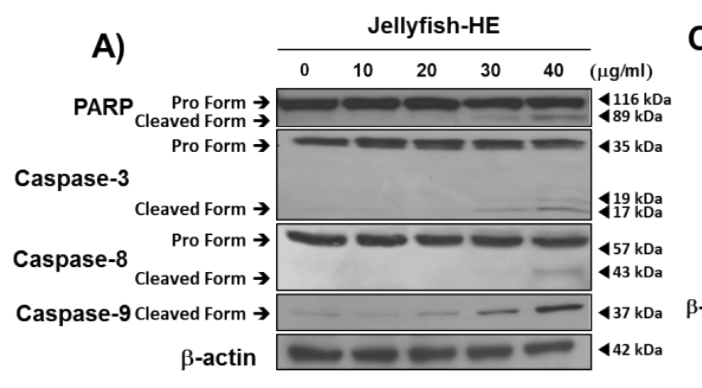

C)

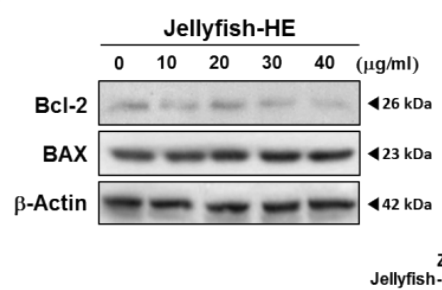

E)

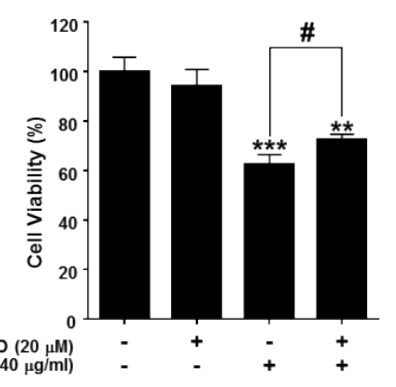

B)

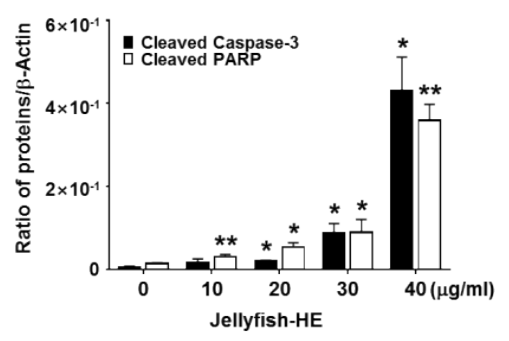

D)

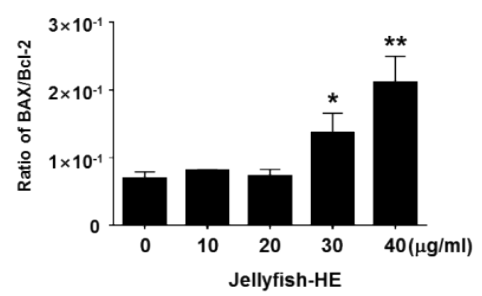

F)

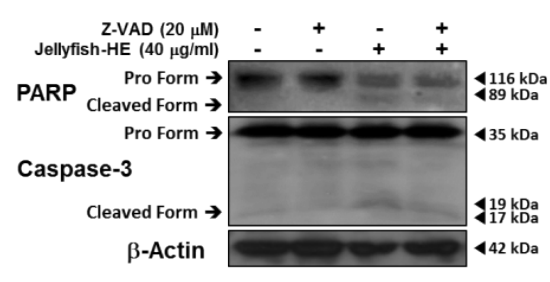

Figure 4.

561

562

A)

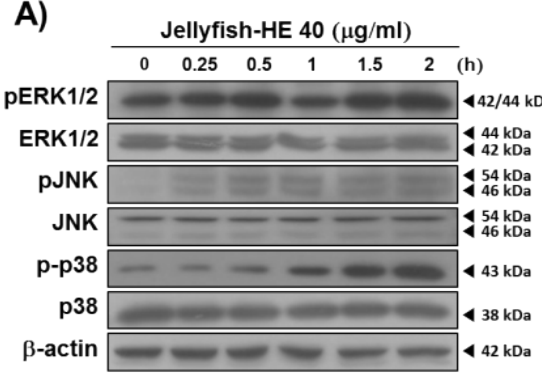

B)

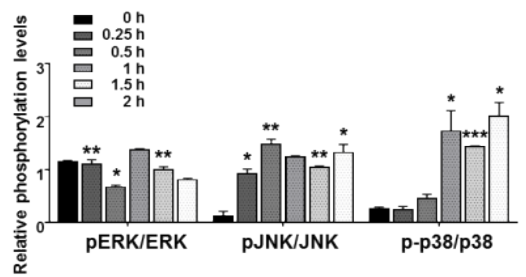

C)

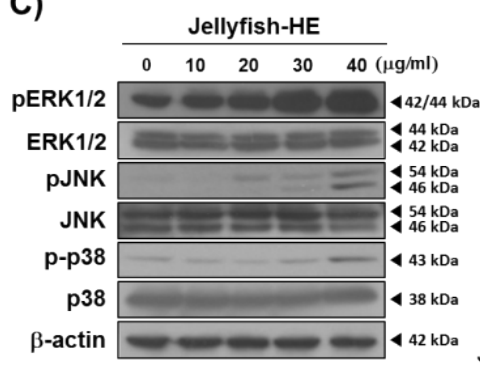

D)

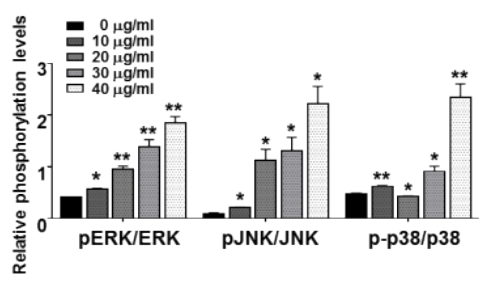

E)

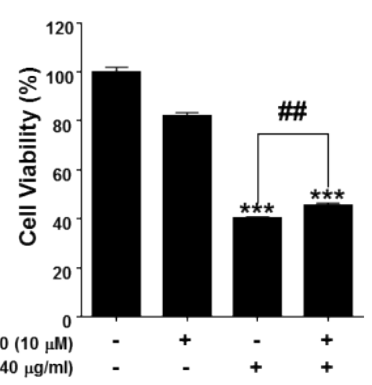

F)

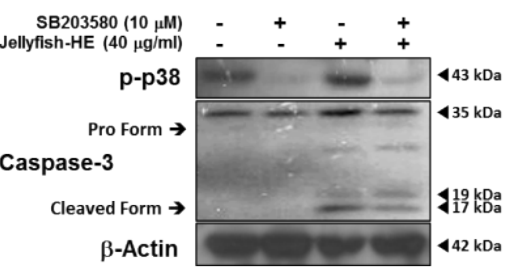

Figure 5. 
A)
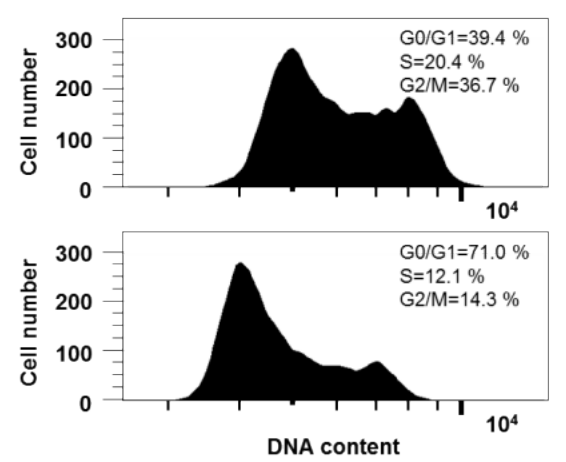

C)

Figure 6.

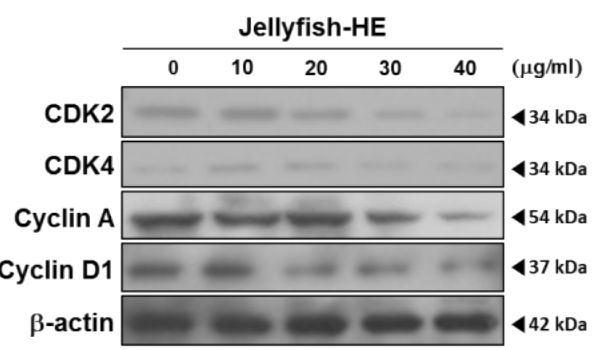

Cleaved caspase-3

$\frac{\downarrow}{\text { PARP }}$
B)

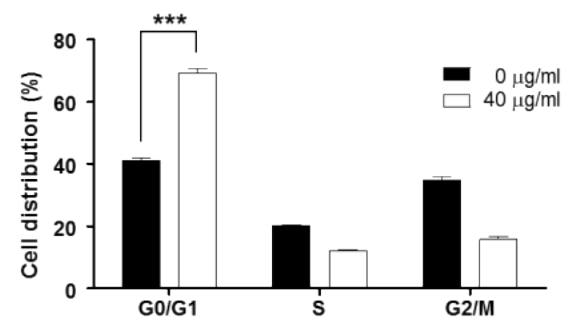

D)

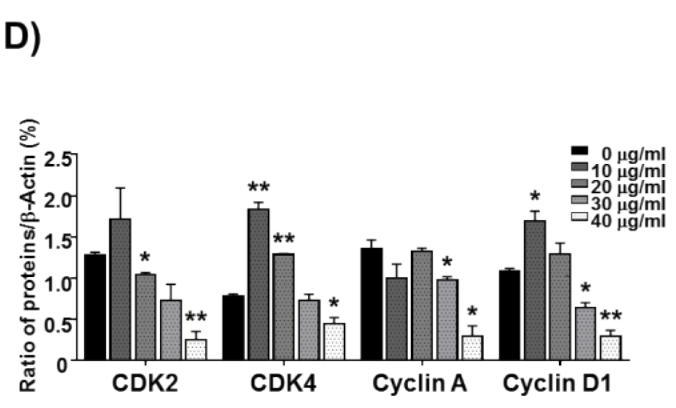

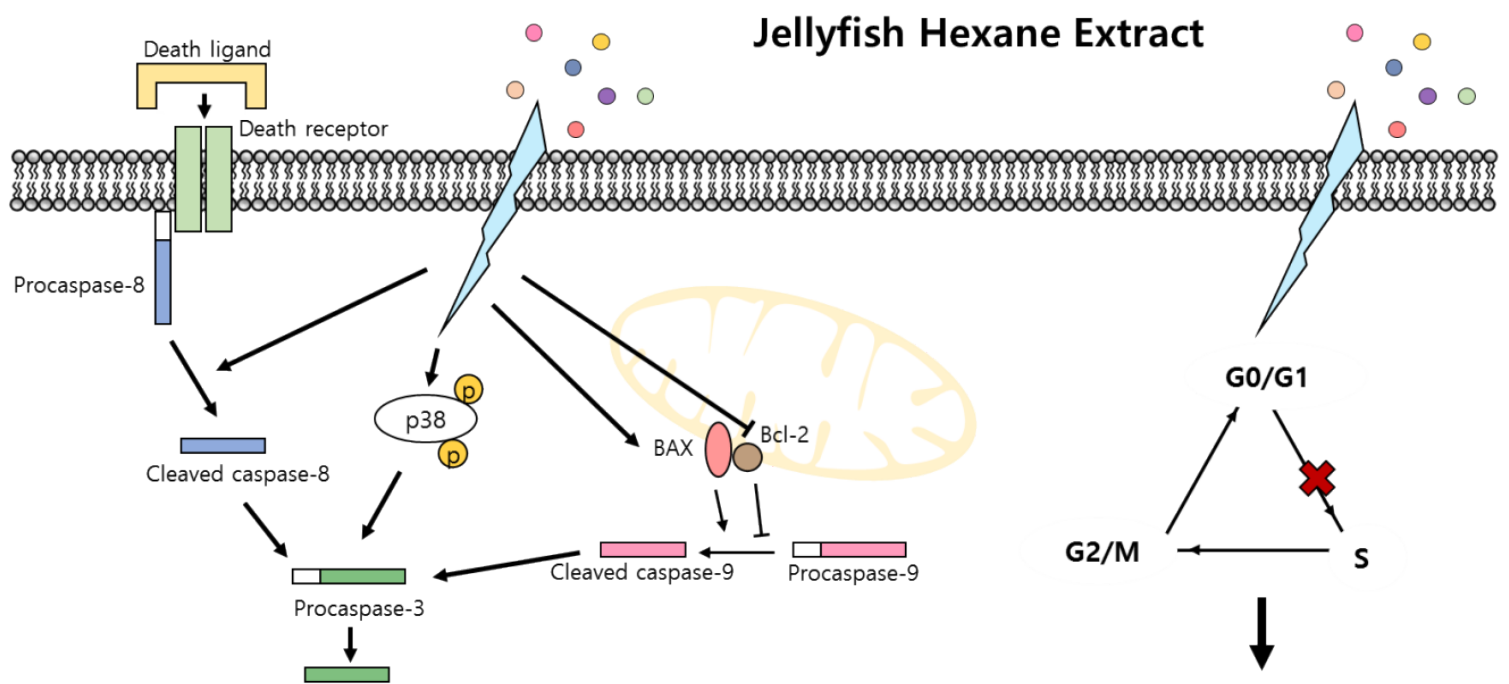

CELL CYCLE ARREST

$\stackrel{\downarrow}{\downarrow_{\text {cleaved PARP }} \longrightarrow \text { APOPTOSIS }}$

$\stackrel{0}{0} \because \begin{aligned} & \text { Jellyfish } \\ & \circ\end{aligned}$


$570 \quad$ Figure 7. 